\title{
Diagnosis Study of the Louga-Ouarack-Ndoyene R31 Regional Road (Senegal)
}

\author{
Seybatou Diop', Meissa Fall'2, Adama Dione' ${ }^{2}$, Moshood N. Tijani ${ }^{3}$ \\ ${ }^{1}$ Institut des Sciences de la Terre, Faculté des Sciences et Techniques, Université Cheikh Anta Diop de Dakar, \\ Dakar, Sénégal \\ ${ }^{2}$ Laboratoire de Mécanique et Modélisation, UFR Sciences de I'Ingénieur, Université of Thiès, Thiès, Sénégal \\ ${ }^{3}$ Department of Geology, University of Ibadan, Ibadan, Nigeria \\ Email: seybdiop@yahoo.fr, meissa.fall@univ-thies.sn, adama.dione@univ-thies.sn, tmoshood@yahoo.com
}

Received 20 December 2014; accepted 15 January 2015; published 19 January 2015

Copyright (C) 2015 by authors and Scientific Research Publishing Inc.

This work is licensed under the Creative Commons Attribution International License (CC BY).

http://creativecommons.org/licenses/by/4.0/

(c) (i) 0 pen Access

\begin{abstract}
The degree of structural damage of the Louga-Ouarack-Ndoyene R31 regional road was surveyed using Lacroix deflectographe and geotechnical testing, in order to recommend possible rehabilitation measures aimed at maintaining the high level of service over the projected life span of the road. The data processing and interpretation were essentially based on the French standards and specifications, through which synthetic variables were generated with a qualitative significance and on the basis of which the extent of repairs and rehabilitation works to be undertaken were suggested. The decision grid thus produced, revealed road structure quality indices of mostly Q3, Q4, and Q5 types for a segment length of $36.954 \mathrm{~km}$ (equivalent to some $69.44 \%$ of the total road section), which justifies some major reinforcement works. The remaining part of the road section (nearly $30.56 \%$ with road quality indices $\leq$ Q2) is still in acceptable condition, requiring only some minor maintenance works. The rehabilitation costs were estimated to be of the order of $5,352,000,000$ (five billion three hundred fifty-two million) CFA francs, based on local market price conditions.
\end{abstract}

\section{Keywords}

Senegal, Road Diagnosis, Lacroix Deflectograph, Deflection, Reinforcement, Maintenance

\section{Introduction}

As part of the mission of regular follow-up of the Senegalese' network of "classified roads' system", the 
SENELABO-BTP laboratory conducted a diagnostic study of the R31 regional road, on behalf of AGEROUTESenegal (Agence des Travaux et de Gestion des Routes du Sénégal). The goal was to identify renovation/rehabilitation works required in order to maintain the level of service after the projected lifetime of over 10 years.

For this study, three complementary indicators to provide assessment on the road edifice were analyzed: 1) its structural behavior (viz., the deformability of the road under the effect of a rolling load); 2) the appearance of the road surface characteristic (apparent pavement damages); and 3) the geotechnical properties of the constituent materials of the various layers of the road. The focus of this paper is to present the methodological approach and the investigations results, the outcome of which can be of advantage to the Senegalese Road Administration as new tools in road diagnosis techniques.

\section{Materials and Methods}

\subsection{Materials}

Site description and road structure: Figure 1 is a lay-out plan showing the study road R31. Out of a length of about $53.500 \mathrm{~km}$, the R31 regional road supports a T2 traffic type (viz., a traffic type with up to 1000 vehicles/ day). It was built in 1998 with the key mission of serving the traffic of people and goods, and for the transport of merchandises from the rural economy within the regional administration of Louga; a district that accounts for approximately 678,000 inhabitants and covers an area of about $29,200 \mathrm{~km}^{2}$.

In terms of geomorphology, this area is characterized by the extension of relatively flat and open landscapes of sand dune systems (quaternary ergs). The climatic conditions are typically Sahelian, with nearly $70 \%$ of the

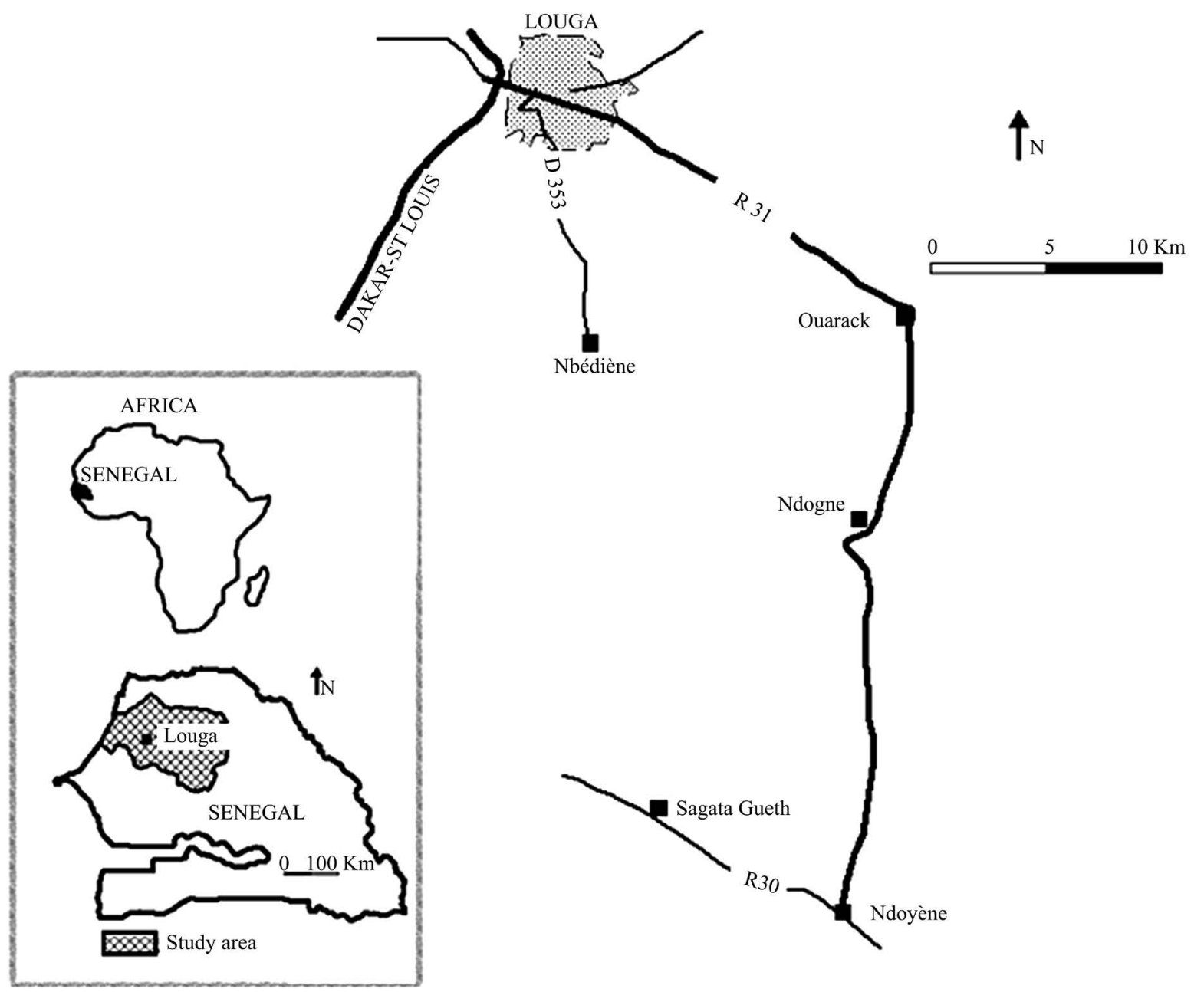

Figure 1. Location map of the study road. 
annual precipitation occurring between the months of July and September. The average annual rainfall places the region between the isohyets $300-400 \mathrm{~mm}$, which implies a savanna vegetation system. The land use is mainly for the cultivation of groundnuts and millet; but truck and cattle ranching are also important in the area.

The studied road comprises of a $5 \mathrm{~cm}$ thick layer of asphalt (bituminous pavement), a base layer of $20 \mathrm{~cm}$ lateritic gravel stabilized with cement, a $35 \mathrm{~cm}$ thick foundation (sub-base) layer (clayey sands) and a $40 \mathrm{~cm}$ thick subgrade of sand resting on the sandy original grounds (Table 1).

\subsection{Methods}

The data bank available for the investigations comprised of measurements of the deformability of the pavement structure using the type 02 Lacroix deflectograph (LD) (Figure 2(a)). These data were complemented with other available information such as data from auger holes drilling by hand and mechanical shovel at different PKs, and from the retrieved samples, and data from the VIZIR campaign conducted in May 2012 by the APAVE Sahel company in order to assess the severity of pavement degradations.

The campaign of deflectometric measurements was carried out by SENELABO-BTP Company in December 2012 immediately after the rainy season, which corresponds to the period of the year when water content in the subgrade is high. The bearing capacity of the road layers is minimal at this time period, as compared to the relatively higher values during the dry period. At the moment there are no experimental data in Senegal to be employed for possible seasonal data corrections in relation to the period of measurement. In addition, geotechnical surveys were also conducted in October 2012 by the company SENELABO-BTP. A series of samples were collected at $10 \mathrm{~km}$ interval, beginning from PK 0 (Louga town). The identification tests on sampled materials were performed in the laboratory based on standard tests such as grain size distribution [1]; soils classification [2]; oedometer methods [3]; methylene blue test [4]; CBR test [5]; modified proctor test [6]; water content determination [7].

Data processing was performed based on the standards and technical specifications developed from the results of methodological research in recent years ([8]-[13]) and used as recommendations and decision tools in terms of diagnosis and estimation of the refection' works to keep safety. This enabled us to achieve a good description of the structural conditions of the road, and establish the section to be repaired, as well as the nature of the most realistic rehabilitation measures to be undertaken.

Principle of the Lacroix deflectograph. Mounted on a truck, the Lacroix deflectograph (LD) allowed for quick survey of the pavement structure and coverage of more points per unit time compared to the famous Benkelman beam. Its technical characteristics are presented in Table 2. The LD allows the measurements of the deflection basin (deflection bowl) generated by a passing truck. The instrumental device includes an automatic pilot system of data acquisition, control and processing. The vehicle running at a constant speed (between about $2-4 \mathrm{~km} / \mathrm{h}$ ), thus simulates a passing heavy-weight-truck (axle load $\sim 13.2$ tons), traveling approximately at $70 \mathrm{~km} / \mathrm{h}$ and records at the same time the deformation induced on the road structure (deflection basin; Figure 2(c)) using several sensors (two arrays of geophones distributed along a beam) that records transversal surface profiles. The goal is to measure in real magnitude the response/deformation of the road structure (viz., the bearing capacity of the subgrade and stiffness of the road pavement and thus evaluate its ability to withstand a heavy traffic load). The deflection/deformation is assumed to vary with the stiffness of the road.

Figure 2(b) schematizes the measurement principle of the LD. The operating procedure involved: first, placing of the measuring beam on the surface of the pavement, along the wheel paths between the wheel axles. The vehicle then drives at a steady speed. The measuring beam under the vehicle remains fixed until the rear axle exceeds $10 \mathrm{~cm}$ of the point of measurement. The stress related to the passage of the vehicle causes a deformation

\begin{tabular}{|ccc|}
\hline \multicolumn{2}{|c|}{ Table 1. Structure cross section of the study road. } \\
\hline Depth (m) & Layer & Composition \\
\hline $0.00-0.05$ & Surface course & Asphalt concrete \\
$0.05-0.25$ & Base & Cement treated lateritic gravels \\
$0.25-0.60$ & Foundation & Clayey sand \\
$0.60-1.00$ & Subgrade (platform) & Sands (natural terrains) \\
\hline
\end{tabular}


(b)

(a)

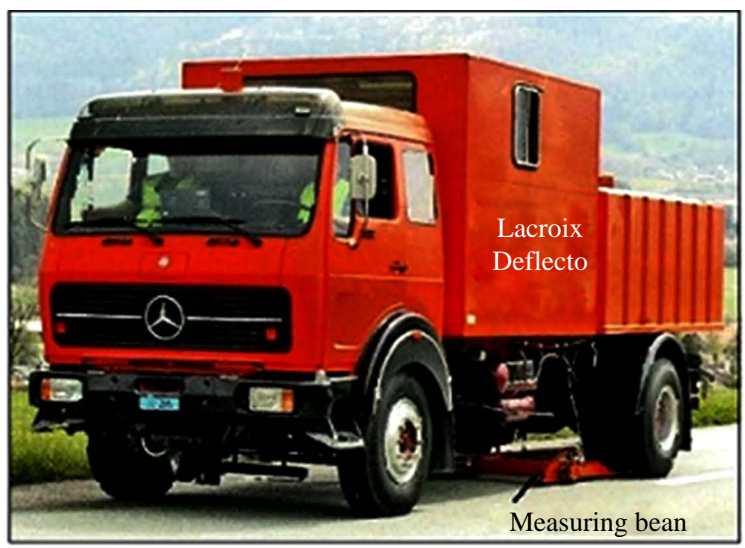

(c)
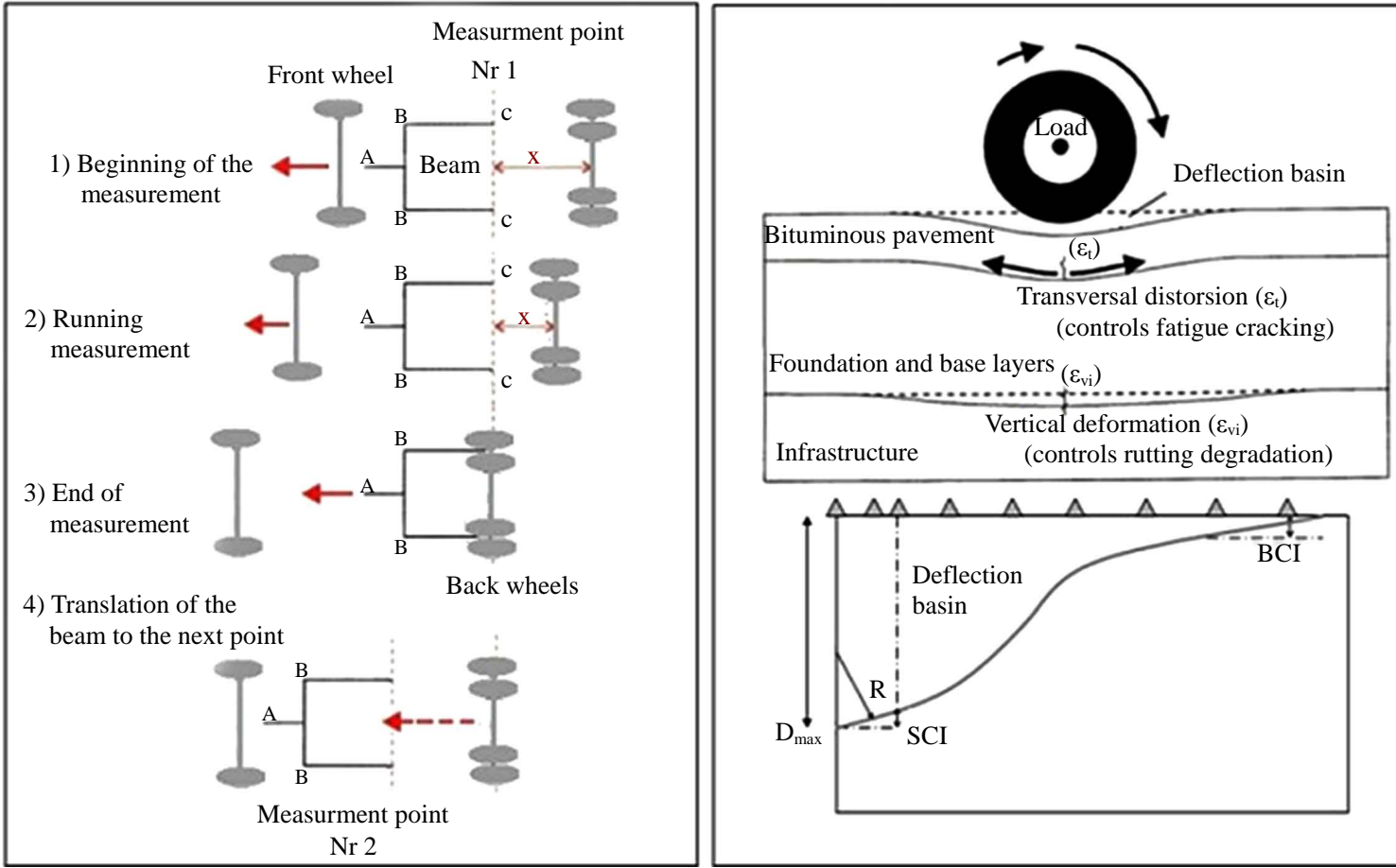

Figure 2. The Lacroix deflectograph: (a) Measurement frame; (b) Measurement principle; (c) Deflection basin and main parameters. ( $\mathrm{D}_{\max }$ is the deflection under the rolling load; $\mathrm{R}$ is the radius of the deflection basin; $\varepsilon_{\mathrm{vi}}$ is the vertical deformation in the subgrade; $\varepsilon_{\mathrm{t}}$ is the transversal deformation in the asphalt concrete (pavement) layer; SCI is the index of surface curvature and BCI represents the index of base curvature) (modified after [14].)

Table 2. Main characteristics of the type 02 LD (modified after [14]).

\begin{tabular}{cc}
\hline Constructor & CECP angers \\
\hline Type of carrier vehicle & GLR 260 \\
Type of electronic device & LEEM \\
Method of load application & Rolling wheel load \\
Speed of applied load & $10 \mathrm{~km} / \mathrm{h}(5 \mathrm{~Hz})$ \\
Vehicle speed & $2-4 \mathrm{~km} / \mathrm{h}$ \\
Measuring step & $4-6 \mathrm{~m}$ interval \\
Sensor resolution & $1 / 100 \mathrm{~mm}$ \\
Location of measures & On the wheel paths between the wheel axles \\
Applied load level & 65 points (flexible pavement) \\
Probed superstructures types & Axles weight 13.2 tons
\end{tabular}


on the road floor which is recorded by the sensors (Figure 2(c)). The deflection basin thus created by the passage of the vehicle is subjected to 65 points of measurement before the system moves forwards over 4 - 6 meters to the next measuring station by pulling the measuring beam. Further details on the measurement principles and procedures are presented elsewhere in cited reference standards and literature (e.g., LPC No. 39 [4]).

However, it should be noted that the resulting data from a LD measurement campaign can be used for various investigation activities and design of pavement structure ([15]-[19]), particularly in the analysis of deflections as indicators of performance (diagnosis and control) as well as in "back-calculations" of the ground E-modules to evaluate the residual modules of the road's component layers and to optimize the prediction for the reinforcement of a pavement structure. There are formulae linking the value of the measured deflection to related "efforts" in the layers and thereby allowing the determination of the structural conditions and critical parameters responsible for the road degradation in terms of ageing and deformation of the pavement at the location of measurement (see Figure 2(c)).

\section{Results and Discussion}

\subsection{Measure of the Road Deformability}

Data from the measurements carried out with the LD road deflection tester were evaluated with the help of the WLFX 32 software (version 6.1.0). The procedure includes: 1) reading the charts records (deflection profiles); 2) conversion into numerical values, after calibration of the sensors, which will allowed for reading the measurements with a precision of $1 / 100 \mathrm{th} \mathrm{mm}$; 3 ) calculating the average value of the maximal deformations/deflecttions $(\mathrm{Md})$ recorded within the deflection basin, and the standard deviation $(\sigma)$ in order to highlight any (possible) heterogeneity within the deflection basin.

In this study, the deflection basin was referred to as a "homogeneous" deformation, if the value of $\sigma$ is $\leq 15 \times$ $1 / 100 \mathrm{~mm}$; and "heterogeneous" when the value of $\sigma$ is $>15 \times 1 / 100 \mathrm{~mm}$. On the assumption of "homogenous" deformation within the basin, the so-called "characteristic deflection" (Cd) of the investigated zone can be defined using Equation (1), the numerical value of which provides guidance on the mechanical behavior of the floor structure and allows for appreciation or diagnosis of the state of the pavement structure at the measurement point (Table 3 and Table 4).

The degree of deformation with respect to passing load depends on the type of road surface (flexible or semi-rigid). For a fully flexible road it was established [20], that there is a relation between the degree of structural damage, the measured Cd-value and the traffic load that have already passed on the road. Under certain conditions the ground modulus (Es) can be estimated based on the Cd-value and the equivalent thickness of the road structure [14]. Cd values can be used to assess the remaining service life of a road floor or to dimension it with respect to the allowable deflection. In this study, the Cd value of a monitored zone was estimated graphically from the Md-value (average deflection), using the following statistical relationship (Equation (1)). That is to say, by assuming a probability level of exceeding the Md value of $10 \%$.

Table 3. Correlation between the parameters Cd, bearing capacity and quality level of a road structure (modified after [3]).

\begin{tabular}{ccccc}
\hline & & Cd values (1/100 mm) \\
\cline { 3 - 4 } & Qualitative appréciation of Cd & Cd1 60 & Medium & High \\
Bearing capacity of the road edifice & Low & Poor & Low \\
Quality level of the road edifice & Good & Doubfull & Bad \\
\hline
\end{tabular}

Table 4. Interval class values for the characteristic deflection [18].

\begin{tabular}{ccccccc}
\hline Deflections class & C1 & C2 & C3 & C4 & C5 & $150-199$ \\
\hline Cd value $(\times \mathbf{1} / \mathbf{1 0 0} \mathbf{~ m m})$ & $0-49$ & $50-74$ & $75-99$ & $100-149$ & High \\
Level of deflexion & \multicolumn{2}{c}{ Low } & Medium & & Very high \\
\hline
\end{tabular}




$$
\mathrm{Cd}=\mathrm{Md}+1.2826 \frac{\sigma}{\sqrt{n}}
$$

Threshold for critical deflections. The procedure of data analysis required establishing "threshold” values as a qualitative basis for appreciating the measured values. Table 3 shows the parameters considered in the process of qualitative data analysis of the road structure in terms of threshold values for the characteristic deflections.

Due to lack of reference value or standard for the Senegalese road network system, the critical threshold values were defined with reference to the "Handbook for Building Flexible Pavements in Tropical Countries” [3].

Thus the following values were adopted in this study (Table 3): Cd1 = $60 \times 1 / 100$ th mm (threshold value below which the structure behaves satisfactorily) and $\mathrm{Cd} 2=1 / 100 \times 80 \mathrm{~mm}$ (threshold value above which the structure has bearing defects). These limits normally characterize the road structures for which constituent materials have been emplaced mechanically. The numerical values may vary in principle according to the geographical location and the local climatic conditions, and are normally derived from an experimental validation procedure based on a series of LD measurements' campaigns in the area of interest.

It is worth noting at this stage of the discussion that the measurement campaigns resulted in a large data set. The data were then processed in a multistep procedure which allowed for division of the monitored road into some 170 separate sections or segments regarded as homogeneous zones. Each homogeneous zone is regarded as a zone where the maximal deflection does not vary significantly (standard deviation $\sigma \leq 15 \times 1 / 100 \mathrm{~mm}$ ); in other words, within a homogeneous zone the pavement responds in a similar way to the applied load. Consequently, the decision to take a particular action is based separately on the individual homogeneous zone. For convenience, however, the monitored road section need not be divided into relatively short zones [20], so the minimum length can be set for the survey. In this study a minimum length of $50 \mathrm{~m}$ was arbitrarily adopted for the zones. The large number of the individual zones implied the use of the graphical dual axis mode of representation (Figure 3 and Figure 4) for the parameter values.

Classes of Cd values. These were defined based on Table 4. The distribution pattern (Figure 3) shows a high variability of the values, although suggesting a predominance of the low deflection levels $(\mathrm{Cd} \leq 60 \times 1 / 100$ th $\mathrm{mm}$ ). Since the road has been initially designed to support a T2 traffic class and still exhibits a S3 bearing capacity platform class $(15 \leq \mathrm{CBR} \leq 30$; see Table 6$)$, the levels of deflection could be classified as week to moderate on the most part of the road section length. This would mean a road structure of good to doubtful quality on the road sections. Further discussion on this will be presented later in the subsequent section below.

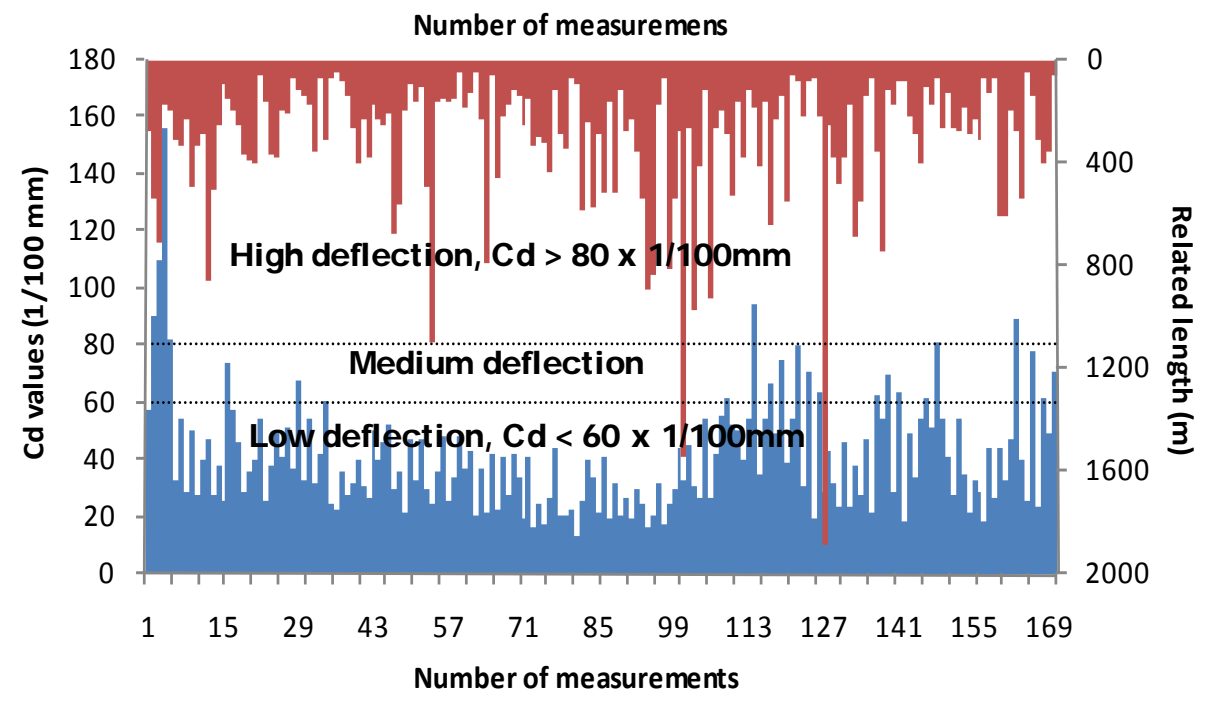

Figure 3. Histogram of section lengths surveyed and their corresponding Cd values. Note the following features of the graph: range of Cd values $<60 \mathrm{~mm} \times 1 / 100$ : low deflection (elevated residual bearing capacity, the road edifice is still good); values range $60 \times 1 / 100 \mathrm{~mm} \leq$ $\mathrm{Cd} \leq 80 \times 1 / 100 \mathrm{~mm}$ : medium deflection (poor residual bearing capacity, the structure of the road edifice is doubtful); Cd values $>80 \times 1 / 100 \mathrm{~mm}$ : high deflection (low residual bearing capacity, the road edifice is bad). 


\subsection{Pavement Damages}

The results of classifying the apparent pavement damages using the index values (Is) derived from the VIZIR study [21] are graphically presented in Figure 4, while the results were also categorized based on Table 5 [22], after some corrections taking into account the recent cosmetic reparation works on the study road. The Is value was calculated by combining the cracking index (If) (i.e. degradation couple: cracking/crazing) with the deformation index (Id) (i.e. degradation couple: deformation/rutting). As shown by the graphic presentation, zones with degradation indices greater than 3 (Is $>3$ ) occur more frequently suggesting that many zones of the road section exhibit large surface structural damages. Consequently, their degradation's level can be characterized as medium to bad which ultimately require that rehabilitation works should be undertaken.

\subsection{Geotechnical Properties of the Road Layers' Constituent Materials}

The results of the laboratory investigations as presented in Table 6 revealed the following facts: 1) The platform (subgrade) is essentially a sand gravel, with a small non-swelling fine fraction of medium plasticity index; whereas materials of the foundation layer (sub-base) are made of clayey sands; 2) The bearing capacity of the subgrade is in the S3 class $(15 \leq \mathrm{CBR} \leq 30)$ over the entire road section, which means it is still suitable. In contrast, the bearing ratio of the sub-base materials $(\mathrm{CBR} \approx 18)$ appeared low, and far below the technical specifications of $30 \leq \mathrm{CBR} \leq 60$. In addition, with CBR indices in the order 55 to 60 , the materials of the base layer (lateritic gravels improved with cement) show some severe bearing defects, compared to the requirements of the technical specifications of CBR range of $\geq 80$ for raw materials and CBR of $\geq 160$ for materials treated with cement.

In summary, the sub-base still kept a proper bearing capacity (CBR $\approx 22)$ and can thus support the ancient pavement structure. However, both the base and the sub-base layers have lost their initial bearing capacity over time, thus causing a considerable structural defect in the road edifice. Based on the poor behavior of the residual surface layers, it is possible to imagine some best feasible rehabilitation solutions. Nonetheless, it should be noted that in general practice, a road edifice, although properly designed, deteriorates with time at the end of its projected useful life span of 10 - 15 years in Senegal. Hence, to maintain its level of service beyond that period,

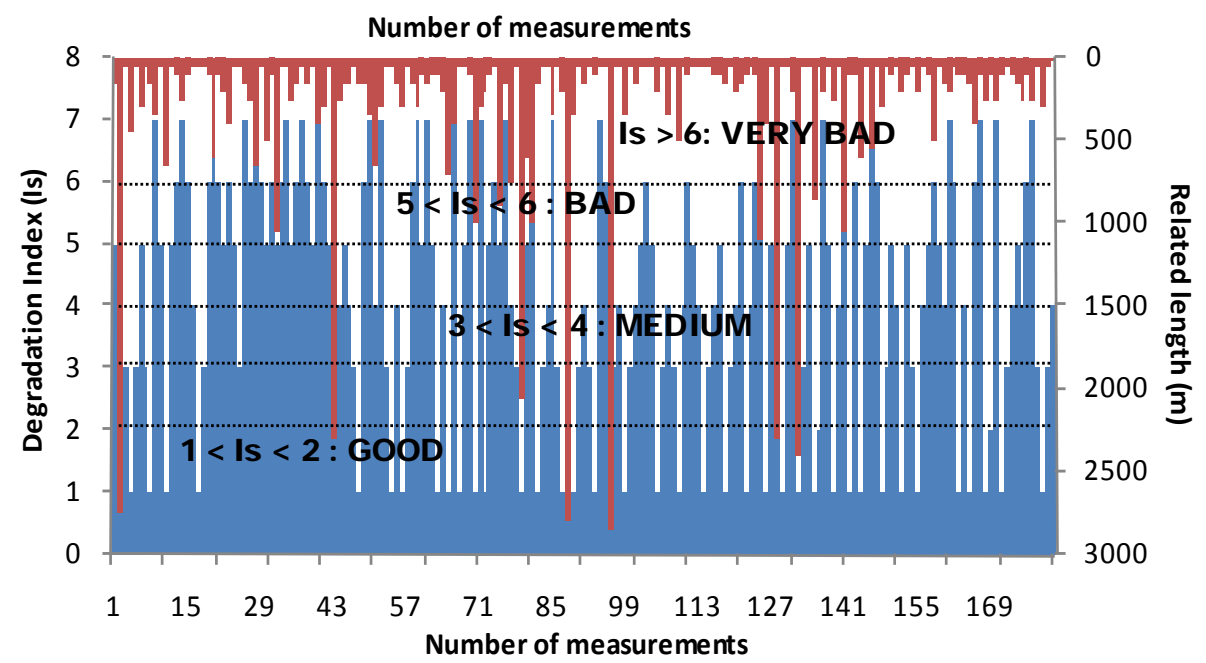

Figure 4. Histogram of the section lengths for surface damages (apparent pavement damages) based on the Is index [21]. Note: A comparison with Figure 3 suggests a fairly close correspondance between road segments' length with high Dc values and those with high Is values.

Table 5. Interval of definition for the index (Is) of surface deterioration on the pavement (VZIR method, [22]).

\begin{tabular}{ccc|cc}
\hline Is values & $1<$ Is $<2$ & $3<$ Is $<4$ & $5<$ Is $<6$ & Is $>6$ \\
\hline Quality of the pavement & Good & Medium & Bad & Very bad \\
\hline
\end{tabular}


it must be repaired, usually by constructing a new base layer of cement improved lateritic gravels and capping it with a bituminous pavement cover.

\subsection{Summary of the Diagnosis Study}

The frequency distribution of the Cd classes, as defined based on Table 4 and presented in Figure 5(a), revealed that the C1 and C2 class levels are largely dominant, as already shown in Figure 3. In addition a cumulative length of approximately $47,686 \mathrm{~m}$ (that is about $89.67 \%$ of the total length of the road section) has Cd values in the $\mathrm{C} 1$ and $\mathrm{C} 2$ class levels; thus exhibiting low deflections. This implies a good bearing capacity of the road structure and a relatively good to moderate road quality level. In contrast, a cumulated length of 3,212 m (corresponding to $6.04 \%$ of the total length of the road) has Cd values of medium C3 class level which implies a questionable (doubtful) road structure quality level, while a section of 2,279 $\mathrm{m}$ (about $4.29 \%$ of the road length) exhibited a road structure in the bad quality category (i.e. C4 and C5 class levels).

With reference to Table 7 [3] which orients the choice of possible solutions in tropical countries according to the profile of Cd values and the apparent surface deteriorations of a road, it can be seen in Figure 5(b) that most of the monitored road sections have quality level of the order $\geq$ Q3, which imply a doubtful road quality and the necessity for further investigations.

Table 6. Geotechnical properties of the road layers.

\begin{tabular}{|c|c|c|c|c|c|c|c|c|c|c|c|c|c|c|c|}
\hline \multirow[b]{2}{*}{ Parameters } & \multicolumn{3}{|c|}{ PK0 au PK9 } & \multicolumn{3}{|c|}{ PK10 au PK20 } & \multicolumn{3}{|c|}{ PK21 au PK31 } & \multicolumn{3}{|c|}{ PK32 au PK42 } & \multicolumn{3}{|c|}{ PK43 au PK53 } \\
\hline & $\mathrm{BL}$ & FL & $\mathrm{PF}$ & $\mathrm{BL}$ & FL & $\mathrm{PF}$ & BL & FL & $\mathrm{PF}$ & $\mathrm{BL}$ & FL & $\mathrm{PF}$ & $\mathrm{BL}$ & FL & $\mathrm{PF}$ \\
\hline $\begin{array}{l}\text { Grain size fraction } \\
\quad<80 \mu \mathrm{m}(\%)\end{array}$ & 12.30 & 9.90 & 9.60 & 13.10 & 9.30 & 10.10 & 13.80 & 10.80 & 10.20 & 12.30 & 10.00 & 9.10 & 13.50 & 9.10 & 10.60 \\
\hline $\begin{array}{l}\text { Grain size fraction } \\
\quad<2 \mathrm{~mm}(\%)\end{array}$ & 29.00 & 97.10 & 99.60 & 29.40 & 96.90 & 99.50 & 31.90 & 96.80 & 99.20 & 32.60 & 93.80 & 98.90 & 30.70 & 94.30 & 98.70 \\
\hline Liquidity limit & 40.30 & - & - & 40.80 & - & - & 32.30 & - & - & 30.30 & - & - & 30.70 & - & - \\
\hline Plasticity index & 23.00 & - & - & 22.90 & - & - & 21.40 & - & - & 16.40 & - & - & 16.20 & - & - \\
\hline GTR classification & B6 & $\mathrm{B} 2$ & B2 & B6 & B2 & $\mathrm{B} 2$ & B6 & B2 & B2 & B6 & B2 & B2 & B6 & B2 & B2 \\
\hline$\gamma \mathrm{d}_{\max }\left(\mathrm{T} / \mathrm{m}^{3}\right)$ & 2.24 & 1.74 & 1.73 & 2.24 & 1.99 & 1.69 & 2.26 & 1.76 & 1.77 & 2.25 & 1.78 & 1.78 & 2.22 & 1.80 & 1.79 \\
\hline W OPM (\%) & 5.20 & 9.90 & 10.00 & 5.00 & 7.60 & 10.60 & 4.40 & 10.00 & 9.60 & 5.00 & 11.20 & 11.40 & 6.60 & 11.00 & 11.20 \\
\hline$\gamma \mathrm{d}(95 \%$ OPM T/m³) & 2.13 & 1.65 & 1.64 & 2.12 & 1.89 & 1.61 & 2.14 & 1.67 & 1.68 & 2.14 & 1.69 & 1.69 & 2.11 & 1.71 & 1.70 \\
\hline CBR index & 58.00 & 17.00 & 24.00 & 57.00 & 18.00 & 22.00 & 61.00 & 19.00 & 22.00 & 60.00 & 18.00 & 21.00 & 55.00 & 19.00 & 21.00 \\
\hline MBV (g/100g) & - & 0.30 & 0.40 & - & 0.30 & 0.40 & - & 0.30 & 0.50 & - & 0.40 & 0.50 & - & 0.40 & 0.50 \\
\hline
\end{tabular}

(Symbols: BL: base layer; FL: fundation layer; PF: plateforme layer).

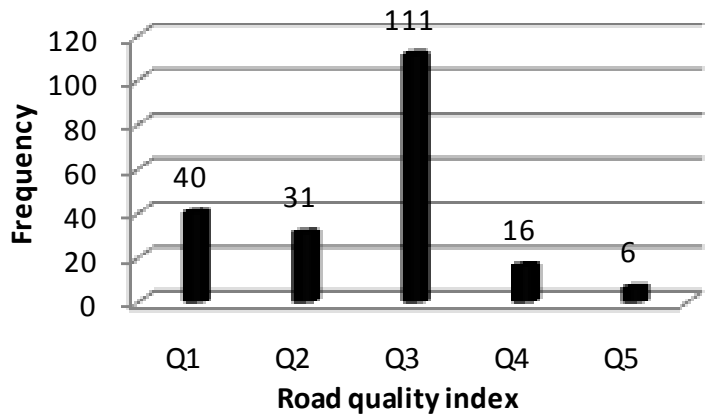

(a)

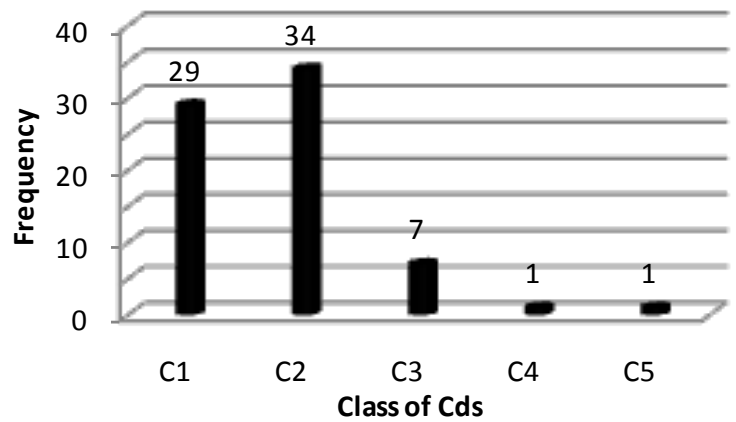

(b)

Figure 5. Frequency distribution of the road quality levels (a) and the Cd classes for the monitored road. (Note: The deflection classes $C_{i}$ are defined in Table 3 , while the quality indices $\mathrm{Q}_{\mathrm{i}}$ are given in Table 7). 


\section{Recommended Rehabilitation Works}

Based on the statistics derived from the qualitative ranking (categorization) of the levels of degradation, individual segments' length upon which corrective measures are required were recognized. Such corrective measures take into account the diagnostic results and type of traffic the road was supposed to carry (viz., one equivalent to the T2 traffic type). The recommended solutions to improve the quality of the study road edifice and thus maintain its level of service are: 1) performance of some maintenance works on road sections with quality levels of $\leq$ Q2; and 2) undertaking of some reinforcement works for those sections with quality indices > Q2.

Table 8 shows the diagnosis results based on the categorization, and the nature of recommended rehabilitation works according to the recommendations presented in Table 9 [3]. For comparative purposes, the table also presents the results of the VIZIR study [21] based mainly on the apparent surface conditions of the monitored road (i.e., simply based on the Is index of apparent surface deterioration).

Based on the above analyses and discussion, this study recommends:

1) some "maintenance" works on road segments with quality levels $<$ Q3; that is to say, a rehabilitation of the road pavement by installing a new asphalt layer coating for the degraded zones. The concerned road length is estimated to be about $16.250 \mathrm{~km}$ (equivalent to $30.56 \%$ of the monitored road section).

2) some "reinforcement or strengthening" works on a distance of $36.924 \mathrm{~km}$ (nearly some $69.44 \%$ of the road length) by providing a new base course of cement treated lateritic gravels (in the usual mixing level of $3 \%$ cement) to address the low bearing capacity of the road edifice, and then setting up a bituminous pavement.

However, the VIZIR study [21] finds that $30.650 \mathrm{~km}$ of study road (approximately $57.64 \%$ of the studied section length) requires some strengthening works, while a length of $22.524 \mathrm{~km}(\sim 42.36 \%$ of the road length) are in suitable condition and would require only minor maintenance works. The discrepancy between the two estimation or evaluation methods is quite substantial; however, the estimates in this study which integrates more index parameters, seems to provide a better understand of the situation of things.

Funding: Further assessment of the cost calculations for the proposed rehabilitation works based on the prevailing market prices revealed a cost estimate in the order of 5,352,000,000 (five billion three hundred fifty-two million) CFA francs, as highlighted in Table 10. This cost assessment scenario, which takes into consideration the uncertainties related to the Q3 class level in some of the road sections, is deemed satisfactory based on the dedicated traffic type and desired quality objective.

The funding should be sources from the major financial institutions (e.g., African Bank for DevelopmentABD and the French Agency for International Development-FAID), which can assist the Senegalese Government in its policy of modernization of the transport infrastructures.

Table 7. Roast decision and parameters taken into account in the development of solutions (modified after [3].

\begin{tabular}{|c|c|c|c|c|}
\hline \multirow{2}{*}{ Road surface appearance } & \multicolumn{4}{|c|}{ Deflections $(\times 1 / 100 \mathrm{~m})$} \\
\hline & Low & $\mathrm{Cd} 1=60$ & $\mathrm{Cd} 2=80$ & High \\
\hline Good [Is $=1]$ & Q1 (maintenace) & \multicolumn{2}{|c|}{ Q2 (maintenace) } & Q3 (?) \\
\hline Cracked but undeformed [Is $=2$ - 3] & Q2 (maintenace) & \multicolumn{2}{|c|}{ Q3 (?) } & Q4 (reinforcement) \\
\hline Deformed and cracked [Is = 4 - 7] & Q3 (?) & \multicolumn{2}{|c|}{ Q4 (reinforcement) } & Q5 (reinforcement) \\
\hline
\end{tabular}

Note: The quality scores Q1 and Q2 indicate the need for maintenance works, while note Q3 indicate questionable road quality and requires further analysis for a final appreciation. The higher-order classes (Q4 and Q5) should receive reinforcement works.

Table 8. Results of the diagnosis study for the R31 regional road-quality of the degradations and consistency of recommendation works.

\begin{tabular}{cccc}
\hline \multirow{2}{*}{ Evaluation criterion } & Good & Medium to very bad & \multirow{2}{*}{ Monitored road length } \\
\cline { 2 - 4 } & (Maintenance) & (Reinforcement) & \\
\hline Quality index (Q $)$ & $16.250 \mathrm{~km}(30.56 \%)$ & $36.924 \mathrm{~km} \mathrm{(69.44 \% )}$ & $53.174 \mathrm{~km} \mathrm{(100.00 \% )}$ \\
Vizir index (Is) & $22.524 \mathrm{~km} \mathrm{(42.36 \% )}$ & $30.680 \mathrm{~km} \mathrm{(57.64 \% )}$ & $53.204 \mathrm{~km} \mathrm{(100.00 \% )}$ \\
\hline
\end{tabular}


Table 9. Recommendations for the types of repairs according to the road quality index and the traffic class T [3].

Q 2 Regular maintenance
Q

Abbreviations: UTG = untreated gravel; BP = bituminous pavement.

Table 10. Details of the proposed repairs and their cost allocations.

\begin{tabular}{|c|c|c|c|c|c|}
\hline $\begin{array}{l}\text { Length of section } \\
\text { to be rehabilitated }\end{array}$ & $\begin{array}{c}\text { Current } \\
\text { service level }\end{array}$ & Type of refection & Nature of the work & $\begin{array}{l}\text { Unit cost } \\
\text { (FCFA/km) }\end{array}$ & $\begin{array}{l}\text { Production } \\
\text { cost (FCFA) }\end{array}$ \\
\hline $16.500 \mathrm{~km}$ & Good & Current maintenance & Point in time & $8,000,000$ & $132,000,000$ \\
\hline $5.500 \mathrm{~km}$ & Medium & $\begin{array}{l}\text { Current maintenance and/or } \\
\text { periodic maintenance }\end{array}$ & $\begin{array}{c}\text { Point in time and/or carpet of } \\
\text { asphalt }(5 \mathrm{~cm})\end{array}$ & $90,000,000$ & $495,000,000$ \\
\hline $10.000 \mathrm{~km}$ & Bad & Periodic maintenance & $\begin{array}{c}\text { Base course in lateritic-cement } \\
\text { and/or surface layer } \\
\text { in asphalt concret }\end{array}$ & $150,000,000$ & $1,500,000,000$ \\
\hline $21.500 \mathrm{~km}$ & Very bad & Reinforcement & $\begin{array}{c}\text { Base course in lateritic-cement } \\
\text { and/or surface layer } \\
\text { in asphalt concret }\end{array}$ & $150,000,000$ & $3,225,000,000$ \\
\hline Total $=53.500 \mathrm{~km}$ & & & & \multicolumn{2}{|c|}{ Total $=5,352,000,000$} \\
\hline
\end{tabular}

\section{Summary and Conclusions}

The structural performance of the R31 regional road was evaluated after more than 10 years of projected service life by means of the Lacroix deflectograph together with other standard methods, while following the French standards and technical specifications used as tools for decision support in road diagnosis and reinforcement.

The study highlights that the main problem lies in a bearing failure of the road structure at some places, following a loss (temporal degradation) of initial properties at the base course and foundation, which show the respective CBR ratios well below the technical specifications. In this particular case, a "reinforcement" aiming at lengthening the service life of the road is recommended, which consists of a layers' replacement. Elsewhere, where the bearing capacity still remains in good condition, it is recommended that the corrective action should consist of some minor "maintenance", by introduction of a new pavement coating for the degraded surfaces. A cost saving scenario for such works has been estimated.

As a form of recommendation, it is essential:

a) to pay a detailed attention to the hydraulic work operations for managing the natural flow and disposal of rain water, by limiting the infiltration on the roadway edges and through carefully executed road shoulders;

b) to carefully study the environment of the road, as well as the hydraulic regime, in order to better understand the origin of the degradations observed on the study road, the rehabilitation of which will allow for revitalization of the agriculture sector which is one of the principal activities in the area. 


\section{References}

[1] Norm NF P 94-056 (1995) Grain Size Distribution.

[2] Norm NF P 11-300 (1992) GTR Sols Classification.

[3] Norm NF P 94-051 et 052 (1993) Oedometer Methods (Atterberg Limits).

[4] Norm NF P 94-068 (1998) Methylene Blue Test.

[5] Norm NF P 94-078 (1997) CBR Test.

[6] Norm NF P 94-093 (1997) Modified Proctor Test.

[7] Norm NF P 94-050 (1995) Water Content.

[8] Centre Experimental de Recherches et d’Etudes du Batiment et des Travaux Publics CEBTP (1980) Guide pratique de dimensionnement des chaussées pour les pays tropicaux. Ministère de la coopération de la république Française, Paris, $155 \mathrm{p}$.

[9] Centre Experimental de Recherches et d'Etudes du Batiment et des Travaux Publics CEBTP (1984) Guide pratique de dimensionnement des chaussées pour les pays tropicaux. Ministère des relations extérieures-Coopération et développement de la république Française, Paris, 157 p.

[10] Centre Experimental de Recherches et d'Etudes du Batiment et des Travaux Publics CEBTP (1985) Manuel pour le renforcement des chaussées souples en pays tropicaux. Ministère de la Coopération de la république française, France, $166 \mathrm{p}$.

[11] Laboratoire Central des Ponts et Chaussées LCPC (1997) Etudes routières: Déformabilité de surface des chaussées. Exécution et exploitation des mesures.Méthode d'essai LPC No. 39, Paris, 71 p.

[12] Centre de Recherches Routières (CRR) (1992) Code de bonne pratique pour le renforcement des chaussées souples à l'aide de materiaux bitumineux. CRR R56/85, Groupe de travail Dimensionnement des chaussées, D/1992/0690/1, Bruxelles, 75 p.

[13] Centre d’Etudes sur les Réseaux, les Transports, l’Urbanisme et les Constructions CERTU (2005) Matériels et méthodes d'auscultation des chaussées urbaines, hors collection. CERTU 2005/6, Lyon, 66 p.

[14] Wurkler, S. (2010) Développement de techniques d'auscultation de chaussées. Projet de Fin d’Etudes, INSA de Strasbourg, Génie Civil Option ATE, 63 p. http://eprints2.insa-strasbourg.fr/634/1/Rapport PFE.pdf

[15] Nkembo, P.M.E. (2013) Mesures des deflections d'une chaussee avec le deflectographe Lacroix: Cas de route regionale R31 Louga-Ouarack-Ndoyene. Memoire IST No. 274, Faculte des Sciences et Techniques, universite Cheikh Anta Diop de Dakar, Dakar, 50 p.

[16] Millien, A., Petit, C. and Takarli, M. (2009) Rapport diagnostic de chaussée du CD36. Convention entre la Plateforme Travaux Public du Limousin et le Conseil de la Corrèze, Université de Limoges, 14 p. http://www.pft-travauxpublics-limousin.com/files/annexe6.pdf

[17] Henia, M.O. and Braber, R. (2008) Falling Weight Deflectometer et Déflectographe Lacroix: Comparaison, Domaine d'Application et Perspectives. Suisse, $6 \mathrm{p}$. http://www.infralab.ch/wp-content/uploads/2013/12/Article-RT-Comparaison-HWD-et-Lacroix.pdf

[18] Association Française de Normalisation AFNOR (1991) Norme NF P 98-200-1—Essais relatifs aux chaussées. Mesure de la déflexion engendrée par une charge roulante. Partie 1: Définitions, moyens de mesure, valeurs caractéristiques. 1991/7, Paris, 6 p.

[19] Association Française de Normalisation AFNOR (1993) Norme NF P 98-200-3—Essais relatifs aux chaussées. Mesure de la déflexion engendrée par une charge roulante. Partie 3: Détermination de la déflexion avec le déflectographe 02. 1993/9, Paris, 6 p.

[20] Andrén, P. (2006) Development and Results of the Swedish Road Deflection Tester. Licentiate Thesis from Royal Institute of Technology Department of Mechanics, Stockholm, 95 p. http://www.diva-portal.org/smash/get/diva2:10556/FULLTEXT01.pdf http://www.peterandren.se/licrep/licrep_eng.php\#x1-90001.4

[21] APAVE Sahel (2012) Organisation et exécution d'une campagne d'inspections sommaires sur le réseau routier classé (Routes revêtues de toutes les régions du Sénégal). Rapport Interne, Dakar, 88 p.

[22] Laboratoire Central des Ponts et Chaussées (1991) VIZIR: Méthode assistée par ordinateur pour l'estimation des besoins en entretien d'un réseau routier. LPCP, Paris, 63 p. 
Scientific Research Publishing (SCIRP) is one of the largest Open Access journal publishers. It is currently publishing more than 200 open access, online, peer-reviewed journals covering a wide range of academic disciplines. SCIRP serves the worldwide academic communities and contributes to the progress and application of science with its publication.

Other selected journals from SCIRP are listed as below. Submit your manuscript to us via either submit@scirp.org or Online Submission Portal.
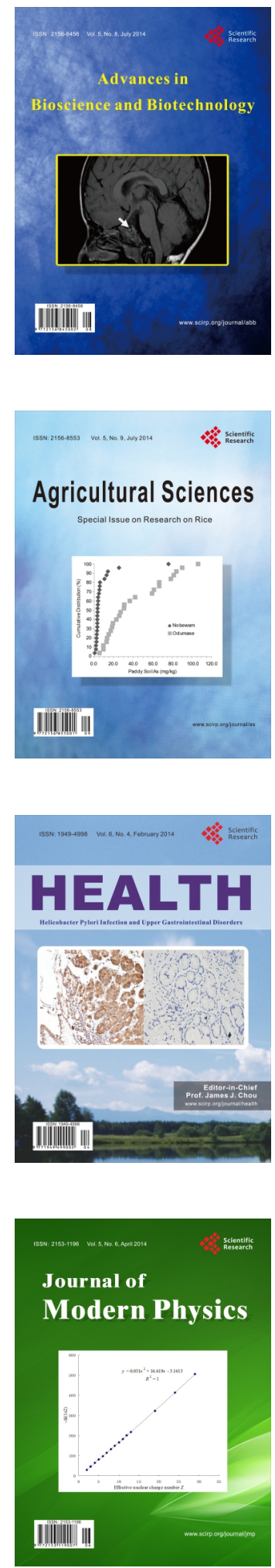
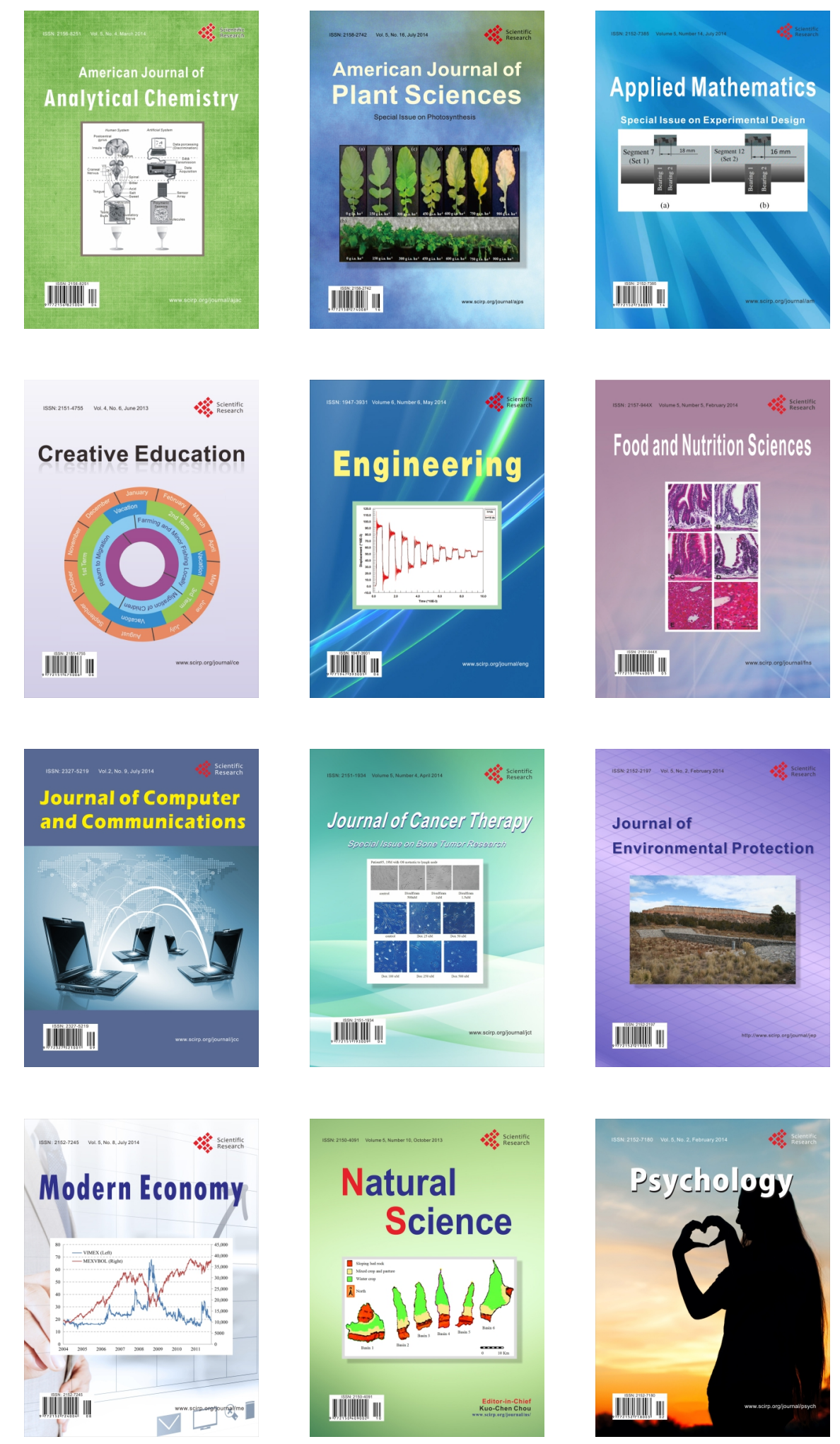